\title{
IDENTIDAD Y LITERATURA
}

\author{
Grínor RoIO
}

Hablar de identidad es hablar de autenticidad, esto es, de la consecuencia que el aparecer en el mundo de algo o de alguien mantiene respecto de un sí mismo que es previo y al que es posible definir de diferentes maneras. Por eso, cuando el lógico H.W.B. Joseph reflexiona sobre la "Ley de identidad" pone en juego dos términos y dice que dicha ley puede formularse planteando que "lo que sea que es es' o, simbólicamente, que "A es A"l. Ahora bien, las definiciones que logran elaborarse a partir de esta plataforma teórica de fondo se movilizan a lo largo de un mosaico que abarca desde la definición esencial o esencialista. de acuerdo con la cual la consecuencia que aquí nos interesa subrayar es la de la apariencia con una esencia o un ser, hasta la meramente nominativa, de acuerdo con la cual la consecuencia es la de la apariencia con un determinado discurso. Es en este último sentido que. refiriéndose a la "identidad latinoamericana" y a las "identidades nacionales" (de cualquier geografía, supongo), afirma José Joaquín Brunner que ellas son "entidades que sólo existen según las formas como hablamos de ellas" ${ }^{2}$. Por alguna razón que a mí no me parece por completo persuasiva y que pone el acento en la posesión en tales casos de un "inconsciente", una "conciencia" y una "personalidad", en su pensamiento las identidades individuales no se hallan sometidas a la misma regla.

Naturalmente, la primera de las dos vías de definición que yo acabo de enunciar es la "dura" o "pesada" y su resultado pragmático no puede ser otro que la rigidez, la oposición testaruda y no pocas veces violenta a todo cambio. En el extremo contrario. la segunda es una vía "blanda" o "liviana" y lo que en ella se da por descontado es la disponibilidad máxima, la más completa apertura del ente a las transformaciones: un discurso puede reemplazarse por otro sin más requisito que la mediación de un simple criterio de conveniencia. Dejo de ser el que soy porque, dadas las particulares circunstancias que me rodean. sociales, políticas, económicas o de cualquier otra indole, eso es lo que me conviene hacer. porque me resulta útil "renovarme", porque es ventajoso que yo comience a actuar de una manera distinta a la que he privilegiado hasta hoy. Para ello, construyo un nuevo discurso acerca de mi fundamento. fabrico con nuevas palabras una nueva edición de mi ser.

También en literatura hablar de identidad es hablar de autenticidad. En esta ocasión, se tratará del vínculo que mantienen una cierta clase de textos con respecto de un fundamento al que

H.W.B. Joseph. An Introduction to Logic. Oxford. Oxford Lniversity Press. s.f., p. 13.

José Joaquín Brunner. "Escenificaciones de la identidad latinoamericana" en Cartografias de la Modernidad. Santiago de Chile Dolmen, s.f, p. 191 
se juzga respetable por no importa qué motivos y al que se subentiende que esos textos tendrían que serle fieles. Una literatura sin identidad es así una literatura "inauténtica" y una literatura inauténtica es una literatura que está siendo infiel con cualesquiera que se presume que son sus obligaciones de comportamiento.

Una serie de supuestos se encuentran involucrados en la formulación anterior. El primero de ellos es el supuesto representacional, es decir, la petición de principio de acuerdo con la cual el lenguaje de la literatura, como ocurre con los demás lenguajes, nos remite a un algo que está fuera de él. Cuando por ejemplo en el lenguaje cotidiano yo digo que "Perico de los Palotes es un tipo muy elegante", quien me está escuchando sabe que mis palabras aluden a un individuo que no está él mismo en el lenguaje, que por el contrario habita en algún barrio del mundo, al que el auditor/la auditora puede/n ver y tocar si es que así se lo propone/n y al que el lenguaje -que son mis palabras en su carácter de signos- sustituye/n y re-presenta/n. Pues bien, hay quienes enfáticamente sostienen que (o mecánicamente actúan como si) en el lenguaje de la literatura las cosas ocurrieran de igual modo. El convencimiento de dichas personas es que no existe una distancia mensurable entre el lenguaje de la literatura y el lenguaje de la no literatura, ya que ambos representan a un algo que los sobrepasa, que se encuentra fuera de ellos. Mejor lenguaje será el que mejor represente la "verdad" (y luego tendremos que abocarnos a la dilucidación de este asunto además) de ese algo.

La otra posición, en la que el autonomismo estético ha venido trabajando con una tenacidad de hormiga ciega desde hace ya más de cien años, argumenta que la disolución del lenguaje literario en el lenguaje no literario es una aventura ilegítima, puesto que el lenguaje literario es esencialmente diferente de los otros lenguajes y su "diferencia", la "específica" nada menos, consiste precisamente en el hecho de que eso que el lenguaje literario representa no se encuentra fuera de él. Largos y aparatosos razonamientos se llevan a cabo para demostrar esta tesis. Al fin de esos razonamientos se resuelve lo que podía haberse resuelto en el primer paradero de una expedición pertrechada con tan espléndido equipaje, puesto que venía inscrito en la premisa: que cuando en una novela leemos que "Perico de los Palotes es un tipo muy elegante", lo que debe entenderse es que ese tipo muy elegante habita en la novela y sólo en la novela, que su vida cuenta únicamente para los fines de la literatura, que es una creación del lenguaje literario y nada más. No es lo mismo decir que Perico de los Palotes es un tipo muy elegante en el lenguaje de todos los días, es lo que los teóricos esteticistas nos advierten, que decirlo en el lenguaje de la literatura. Se sigue de lo anterior que el lenguaje de la literatura no es el de la realidad de verdad sino el de la realidad de la fantasía, la imaginación, la ficción. Debo dejar constancia de paso que este segundo paradigma teórico es el que en los estudios literarios latinoamericanos se aquerenció y señoreó sin contrapeso durante el período de la "acelerada y algo caótica modernización" disciplinaria que según Antonio Comejo Polar tuvo lugar entre nosotros en la década del sesenta y hasta principios de la del setenta ${ }^{3}$. Las dos o tres vertientes del estructuralismo, al margen de sus pequeñas y olvidables rencillas, coincidieron en adoptarla como un dogma de fe y en operar metodológicamente a base de ella.

Pero para los propósitos de nuestra exposición, conviene que quede establecido desde ya que si es efectivo que el lenguaje de la literatura no le debe nada a nadie, si no nos cabe duda de que el fundamento de su aparecer en el mundo está dentro de sí mismo y nada más que dentro de sí mismo, entonces hablar a su respecto de identidad o autenticidad adopta la figura del oxímoron o la de la contradictio in adjecto. En el mejor de los casos, podría describirse o calificarse la

"Antonio Comejo Polar. Escribir en el aire. Encayo sobre la heterogeneidad de las literaturas andinas. Lima. Editorial Horizonte. 1094. p. 12 . 
consecuencia de ese lenguaje para con una cierta estilística del decir. para con una cierta escuela retórica, y cualquiera puede ver que eso no es terriblemente interesante.

Por el otro lado, yo me temo que desde los ochenta para acá, y por causas de las que podría dar cuenta pero no es indispensable, la batalla parece estarse inclinando hacia el partido de los indiferenciadores. Si la teoría literaria ha sido desplazada contemporáneamente por la teoría crítica (no la de Francfort, en todo caso) es porque nadie puede decir hoy con la conciencia tranquila qué sea eso de la literatura y si nadie puede decirlo es porque no está claro en absoluto que el lenguaje de la literatura nombre a algo que existe sólo en la literatura. De ahí la boga de los estudios culturales. De ahí que en este ambiente de escasa o ninguna discriminación estén haciendo su agosto "los profesores de literatura francesa que escriben libros sobre los cigarrillos o sobre la manía norteamericana con la gordura, los shakespereanos que analizan la bisexualidad y los expertos en el realismo que están trabajando sobre los asesinatos en serie", como no sin su cuota de impaciencia observa Jonathan Culler ${ }^{+}$. Uno percibe, por debajo de todo eso, la sospecha, confesa o no, de que hablar de literatura como de un quehacer o una práctica peculiar ha acabado por convertirse en una presunción o una futilidad.

Pero acontece que si renunciamos a ese privilegio y si solicitamos un cupo entre las huestes del partido indiferenciador no tardaremos en enfrentarnos con renovadas perplejidades. Angel Rama, por ejemplo, postuló en 1982, en su Transculturación narrativa en América Latina, la existencia de tres "impulsos modeladores" en la historia de nuestra literatura de los siglos XIX y XX. Ellos serían el afán de "independencia", el afán de "originalidad" y el afán de "representación"5. No hace falta ser muy listo para darse cuenta de que el segundo de estos impulsos, la originalidad, es un resultado del primero y que el tercero, el afán de representación. es un resultado del segundo: se quiere ser original porque se es independiente y se quiere ser representativo porque se es original. En resumidas cuentas. el hilo que va de la independencia a la representatividad está a la vista para todo aquel que se interese en constatarlo y es el que fija las normas de todo el proceso. Nuestra literatura vino al mundo con el estallido de la independencia política, espoleada por un deseo de desasociación respecto del "centro" hegemónico de entonces, y después no quiso o no pudo renunciar a ese prurito identitario en lo esencial porque la desaparición del primer "centro" no sólo no impidió sino que facilitó el posterior intervencionismo de otros. Pero el mismo Rama complementa esa tesis relativa a la existencia de tres rasgos perdurables en la historia de la literatura latinoamericana con otra relativa a su variabilidad. Propone entonces una periodización de nuestra historia literaria en cuatro épocas: la de la independencia y formación de las nuevas naciones (1810-1870), cuando el deseo de representar lo propio es aún joven y fuerte; la del "internacionalismo modernizador" decimonónico (1870-1910), durante el cual la representatividad se repliega por lo menos desde un punto de vista mimético simple; la época nacionalista y social (1910-1940), cuando cobra fuerza de nuevo: y una actualidad compleja, que él no denomina en 1982 (lo hará en La ciudad letrada, cuando la llama "populista", reservando lo de "nacionalista" para la época anterior), que tiene un ala urbana y cosmopolita (Cortázar) y un ala regionalista, o más bien superregionalista, nutrida ésta con la "organicidad cultural" de los "espacios interiores" (Arguedas, Rulfo), y la que se prolongaría, presumiblemente, desde 1940 hasta el tiempo en que él escribe (en La ciudad letrada sólo hasta 1972).

Esto significa que los tres afanes o "impulsos", que según piensa Angel Rama sustentan la continuidad del proceso literario en América Latina, no se mantienen siempre idénticos a sí mismos sino que entran en dinámicas de reconversión en cada una de las épocas indicadas, incluido

Jonathan Culler. Literan Theor. A Very Short Introduction. Oxford. New York. Oxford University Press, 1997, p. 43.

'Angel Rama. Transculturación narrativa en América Latina. México. Siglo XX1. 1982. p. 11 et sqq. 
ahí el afán de representación. No fue lo mismo hacer una literatura latinoamericana representativa en 1850 que hacerla en 1890 que hacerla en 1930 que hacerla en 1950 ó en 1980, y no tanto porque la realidad histórica había cambiado de aspecto en cada una de tales coyunturas, lo que era obvio y esperable, como porque habían cambiado los criterios de comprensión de lo real y los métodos capaces de alcanzar la autenticidad de la representación. El Bello que en 1826 escribe la silva a "La agricultura de la zona tórrida" o el Lastarria que en el "DiscursoÖ" del 42 se suma a los requerimientos de que la literatura sea "expresión de la sociedad"6 entienden por Latinoamérica (para ellos, Hispanoamérica) una cierta cosa y tienen una estrategia para representar esa cosa que nada o muy poco tienen que ver con la conciencia con que hacen suya esa misma tarea un Darío a fines del siglo XIX o un Pablo Neruda a mediados del XX.

Ni lo que se representa ni el cómo se lo representa son pues apuestas fijas. Si esto es así, ¿en qué consiste la vocación identitaria de un texto de literatura? ¿Por qué o cómo podemos decir que una literatura es más auténtica que otra? Es más: ¿cómo podemos acusar a una literatura de desleal o de desidentificada? Sabemos la respuesta a estas preguntas. Se nos argumentará ahora que la vocación identitaria es algo que se pone de manifiesto cuando la literatura de la que tratamos es una hija devota de su propio tiempo, cuando, como quería Sartre, ella "se compromete" con su tiempo. Dos maneras hay para comprobar el compromiso desde un punto de vista crítico, una apoyada en la teoría del reflejo y la otra en la teoría de la producción del texto o del texto como producción. Las novelas hispanoamericanas que en los años cincuenta se ganaron el aplauso de José Antonio Portuondo fueron por ejemplo aquellas que "reflejaban" bien la tipología humana de la región, aquellas que ofrecían un retrato óptimo de nuestra vida comunitaria: "La novela hispanoamericana se ha nutrido principalmente de la realidad social" ${ }^{7}$. Con este mismo criterio su compatriota Juan Marinello vapuleó al modernismo, diciendo que "fue un fenómeno americano aunque no al servicio de nuestros pueblos" y que "fue el vehículo deslumbrante de una evasión repudiable, el brillante minero de una grieta desnutridora"8. Estaba acusando así a Darío y los demás de inautenticidad, de flaqueza identitaria, de frivolidad y hasta de falta de patriotismo. La contraparte de esa acusación, en él como en Manuel Pedro González y en FranÁoise Perus, es un apasionado ensalzamiento de Martí.

Rama, por su parte, entra también en este debate pero no para contradecir a Juan Marinello en el terreno teórico de Juan Marinello y para celebrar de esa manera la ausencia en el modernismo de un reflejo americano bueno o malo, como con una posición esteticista habían hecho en los años cincuenta y sesenta Raúl Silva Castro y Enrique Anderson Imbert, sino para precisar que el principio de la representatividad puede describirse y aquilatarse haciendo uso de un marco teórico diferente. Para Rama, si bien es cierto que el mundo latinoamericano de fines del siglo XIX no estuvo o estuvo sólo muy parcialmente retratado en la literatura del modernismo, no es menos cierto que el modernismo consolidó "la autonomía poética de la América Española" y que "fue el más ingente esfuerzo creativo de la poesía hispanoamericana, al incorporarse al mercado único cultural y económico que establece la burguesía europea y norteamericana al iniciar la conquista y unificación del mundo entero. Estuvo el modernismo al servicio de los pueblos en la medida en que comprendió la necesidad de apropiarse del instrumental, las formas y los recursos literarios de la literatura creada al calor del universo económico europeo ${ }^{\prime \prime}$. El clash de Rama con Marinello es notorio y, sin que nosotros tengamos que detenernos aquí a discutir las muchas precipitaciones

\footnotetext{
- José Victorino Lastarria. Recuerdos literarios. Santiago de Chile. Zig-Zag. 1968, p. 94 et sqq.

"José Antonio Portuondo. "El rasgo predominante en la novela hispanoamericana" en Juan Loveluck, ed. La norela hispanoamericana. Santiago de Chile. Universitaria. 1969. p. 90.

${ }^{8}$ Juan Marincllo. Ensaros martianos. Las Villas. Lnirersidad Central de Las Villas, 1961, p. 172.

${ }^{9}$ Angel Rama. Rubén Dario yel modernismo. Circunstancia socioeconómica de un arte americano. Caracas. Lniversidad Central de Venezuela. 1970 . pp. 5 y 124.
} 
historiográficas y sociológicas que debilitan el pensamiento del estudioso uruguayo, podemos ver que lo que él está haciendo en su libro es laudable como quiera que sea, pues lo que procura es oponerle a una perspectiva analítica y evaluadora de la representatividad estrecha, que opera con el respaldo de la teoría del reflejo, otra más generosa, que presta atención a los procesos de producción de los artefactos estéticos. El modernismo sería al fin de cuentas representativo, sólo que no de la manera con que Juan Marinello entiende la cuestión.

Este distingo es de gran importancia sin duda, porque sin ir más lejos una crítica reflexionista, que tenga como modelo el realismo tradicional, como las de Portuondo o Marinello (y la de Lukács, dicho sea de paso, si no recuérdese su furibundo "La ideología del modernismo", de 1955, donde lo sorprendemos argumentando que el arte moderno no sólo no lleva al enriquecimiento del arte sino que termina en su negación), no va a estar en condiciones de medir la representatividad de la literatura de vanguardia. Nada saca Portuondo con decir que "Pretender hallar información válida sobre un país cualquiera en sus obras literarias, además de inaceptable aberración estética, constituye peligrosísima falacia" ${ }^{\prime \prime}$. Esas son palabras huecas, declaraciones que no pasan de ser gestos de buena crianza. Lo concreto es que neutralizar esa falacia a la que él se refiere es algo que su propia crítica, una crítica de corte reflexionista y sospechosa por lo tanto de de "las angustias aprendidas y las náuseas fabricadas". no está en condiciones de hacer. En cambio, una crítica como la que Rama nos propone puede conjugar cómodamente el desempeño de un arte no realista con el impulso representacional. Basándonos en una propuesta como la suya podemos entender lo que no entienden ni Lukács ni Portuondo ni Marinello: que la revolución que en el arte del siglo XX se desencadena a partir de los experimentos del impresionismo. y que después se prolonga y se perfecciona en la vanguardia y en la postvanguardia, no es una revolución que se libra para darle con la puerta en las narices al principio de la representatividad. Por ei contrario, su propósito es que el principio de la representatividad se cumpla con más eficiencia todavía, porque ahora él va a ser garante de una comprensión de lo real que incluye la variación temporal mínima, y de unas metodologías representacionales que dan comienzo a la desarticulación del objeto concebido hasta entonces como un todo homogéneo y que no son ni pueden ser ya las del realismo decimonónico. También se entiende en este contexto una observación como la que hace Néstor García Canclini acerca de las artes visuales latinoamericanas de la década del ochenta. las que para representar nuestra identidad "hibrida" estaban haciendo uso de "una mirada geométrica, constructiva, expresionista, multimedia, paródica"i. El resultado es que, en sentido estricto, para el nuevo arte, el del impresionismo, el de la vanguardia, el de la postvanguardia y hasta el de la ultravanguardia, el realismo decimonónico es un arte irrealista, es un arte inauténtico, desidentificado respecto de las urgencias y aspiraciones de nuestro tiempo y hasta, por qué no, respecto de las urgencias y aspiraciones del suyo propio.

Con lo que vamos a dar en el turf de Borges. En "El escritor argentino y la tradición" Borges se ocupa de la consecuencia que según la opinión de algunos espíritus ingenuos los escritores de ese país tendrían que guardar para con un antes (cualquiera) de carácter nacional y al que esos escritores debieran serle fieles. Expone a propósito de esto su escepticismo primero en cuanto a las bondades epistemológicas de la teoría del reflejo y lo hace de la siguiente manera: La idea de que la poesía argentina debe abundar en rasgos diferenciales argentinos y en color local argentino me parece una equivocación. Si nos preguntan qué libro es más argentino, el Martín Fierro o los sonetos de La uma de Enrique Banchs, no hay ninguna razón para decir que es más argentino el primero. Se dirá que en La urna de Banchs no está el paisaje argentino, la topografía argentina, la botánica argentina, la zoología argentina; sin embargo, hay otras

"El rasgo...", 93-94.

Néstor Garcia Canclini. Culturas hibridas. Estrategias para entrar y salir de la modemidad. México. Grijabo. 1989 . p. 125. 
condiciones argentinas en La uma [...] yo diría que en el manejo de estas imágenes convencionales, en esos tejados y en esos ruiseñores anómalos, no estarán desde luego la arquitectura ni la ornitología argentinas, pero están el pudor argentino. la reticencia argentina; la circunstancia de que Banchs, al hablar de ese gran dolor que lo abrumaba. al hablar de esa mujer que lo había dejado y había dejado vacio el mundo para él, recurra a imágenes extranjeras y convencionales como los tejados y los ruiseñores, es significativa: signficativa del pudor, de la desconfianza, de la reticencias argentinas; de la dificultad que tenemos para las confidencias, para la intimidad"1?.

Pero, claro, Borges no es ninguna inocente paloma y no tarda en darse cuenta de que esa es la guerra de la que a el le resulta más cómodo salir victorioso: la que se limita a hacer el reemplazo de un reflejo obvio por otro un poco menos obvio. ombúes por tejados, gauchos por ruiseñores. Si exceptuamos la no tan desanudable paradoja de que los ruiseñores se transformen en símbolos de la nacionalidad argentina. no hay en efecto una diferencia sustantiva entre uno y otro de esos dos imaginarios. Da Borges, por consiguiente, un paso más audaz: "He encontrado días pasados una curiosa confirmación de que lo verdaderamente nativo suele y puede prescindir del color local: encontré esta confirmación en la Historia de la declinación y caída del Imperio romano de Gibbon. Gibbon observa que en el libro árabe por excelencia. en el Alcorán, no hay camellos; yo creo que si hubiera alguna duda sobre la autenticidad del Alcorán, bastaría esta ausencia de camellos para probar que es árabe [...] un falsario, un turista, un nacionalista árabe, lo primero que hubiera hecho es prodigar camellos, caravanas de camellos en cada página"1.3. El remate forzoso (y gozoso) de este descubrimiento borgeano, muy de su firma desde luego, es una nueva y más potente paradoja: un libro será más auténtico, poseerá una identidad más acusada, estará más comprometido con lo que sea que tiene que o quiere estar comprometido en la medida en que se dé en él una adscripción identitaria que sea inversamente proporcional al esfuerzo que se ha hecho para demostrarla. Ponerse a demostrar la autenticidad, la identidad, el compromiso es cosa de "falsarios", de "turistas" y de "nacionalistas", dictamina Borges. Uno es el que es porque no puede menos que serlo. Una literatura es la que es porque eso le resulta inevitable. Reflexiona por lo tanto, al fin de su ensayo, tan irónica como melancólicamente: "...o ser argentino es una fatalidad y en ese caso lo seremos de cualquier modo [o sea, puede que recurriendo a la fórmula de Enrique Banchs o a cualquiera otra], o ser argentino es una mera afectación, una máscara"1t.

Pienso que este es el momento en que Borges deja atrás la perspectiva reflexionista y se mueve hacia una estética basada en las condiciones que determinan el proceso de producción de los textos. No obstante su horror por el determinismo ("Si yo voy a tocar la mesa con una de mis manos y me pregunto: ¿la tocaré con la mano izquierda o con la mano derecha?, y luego la toco con la mano derecha, los deterministas dirán que yo no podía obrar de otro modo..." ${ }^{15}$ ), su raciocinio empalma vellis nollis con la tesis sociológica de Rama: Darío y los otros modernistas se propusieron programáticamente no hacer un arte americano, pero no pudieron evitarlo. Operaron de conformidad con un repertorio de posibilidades productivas (en mi propio lenguaje, con un repertorio de modos discursivos ejemplares), el que como quiera que sea se constituyó en una marca en/de sus obras. Fueron auténticos, fueron identitarios, fueron comprometidos pese a todos los intentos que desplegaron para no serlo y a lo peor a causa de tales intentos (Borges dixit), y eso es algo que nosotros los críticos podemos comprobar. Entre el efecto de verdad, esto es, la consecuencia del texto para con la realidad del mundo, y el efecto de ficción, esto es, la

\footnotetext{
"Jorge Luis Borges. "El escritor argentino y la tradición" én Discusión. Obras completas. Buenos Aires. Emecé, 1974. pp. 268269

1.3 Ibid., 269.

14. Ibld. 274 .

I. Ibid.. 273
} 
consecuencia del texto para con su propia realidad. hay. y bien lo sabían Platón y Aristóteles. la posibilidad de un texto cuya consecuencia lo es también respecto de una realidad propia, pero que indirectamente, a través de la construcción de esa realidad propia, no puede dejar de decir lo que dice acerca de la realidad de verdad. El efecto que persigue ese texto es el efecto de verosimilitud. En otras palabras, apela a la credibilidad del lector no en cuanto a la promesa que a éste se le hace de ofrecerle un/a retrato/copia del mundo sino en cuanto a la búsqueda que el texto de marras promete de un sentido para el mundo con cualesquiera sean los medios que él selecciona para completar la faena, y yo creo que de esto exactamente es de lo que estamos hablando cuando hablamos de autenticidad en el campo nunca indiferenciado del todo. pero tampoco nunca diferenciado del todo, de los lenguajes literarios. 